\title{
Impacts and management of common buzzards Buteo buteo at pheasant Phasianus colchicus release pens in the UK: a review
}

\author{
Dave Parrott
}

Received: 18 June 2014 / Revised: 17 December 2014 / Accepted: 21 December 2014 / Published online: 28 January 2015

(C) Crown Copyright 2015. This article is published with open access at Springerlink.com

\begin{abstract}
In the UK, alongside an expanding common buzzard population, there is increasing concern of raptor predation at pheasant release pens. Historically, losses of poults to raptor predation has been low, commonly (90\% of shoots) $\leq 1 \%$ of birds released into pens, representing a small percentage of losses relative to all causes of mortality. A small number of shoots did suffer higher losses, estimated at $>5 \%$ at one in 30 estates and $>10 \%$ at some estates. Predation was lower (i) with increased poult age at release, (ii) in later releases, (iii) in pens with good vegetative cover, (iv) in pens within woods $<50$ acres and (v) in releases of $<500$ birds; there were also indications that predation was greater in high-density releases. Studies found no evidence for indirect losses (i.e. nonpredation impacts of raptor activity, e.g. panic-induced smothering events). Mitigation measures include the following: (i) sufficient vegetative cover (supplemented if necessary, e.g. brash piles), (ii) minimise perching opportunities for raptors, (iii) stock older poults, (iv) stock at recommended densities, (v) reflective tape and scaring devices and (vi) diversionary feeding. Significant gaps in knowledge were identified, including (i) predation being incompletely evaluated in the context of contemporary buzzard populations, (ii) indirect effects not adequately studied, (iii) occurrence of 'problem' individual buzzards is unclear, (iv) adequate field trials of mitigation measures are lacking and (v) level of gamekeepers' adherence to industry recommendations not known. Contemporary studies of these issues are necessary to understand the impacts and to inform management of buzzards at pheasant release pens.
\end{abstract}

\section{Communicated by H. Kierdorf}

D. Parrott $(\bowtie)$

National Wildlife Management Centre, Animal \& Plant Health

Agency, Sand Hutton, York YO41 1LZ, UK

e-mail: dave.parrott@apha.gsi.gov.uk
Keywords Buzzard · Buteo buteo $\cdot$ Pheasant $\cdot$ Phasianus colchicus $\cdot$ Predation $\cdot$ Management

\section{Introduction}

The potential role of predators, real or perceived, as limiting factors of prey populations (Sih et al. 1985; Newton 1993, 1998) has created a number of human-wildlife conflicts (Graham et al. 2005; Thirgood et al. 2005). Conflict occurs where different groups of stakeholders disagree over the management of a species and is frequently manifest in respect to predator species whose populations are, or were formerly, threatened, or are species considered to be charismatic or iconic (Manosa 2002; Woodroffe et al. 2005). For birds of prey, there are long-standing conflicts with gamebird, poultry and other livestock interests, and more recently in respect to avian species of conservation concern (JNCC 2000; Thompson et al. 2003; Valkama et al. 2005; Gibbons et al. 2007).

In most European regions, gamebird hunting is an important socioeconomic activity in rural areas (Manosa 2002; Vinuela and Arroyo 2002). Hunting may also be potentially beneficial to biodiversity, by promoting conservation and management of habitats within a strategy of 'conservation through wise use of natural resources'. However, in some cases, there may be conflicts between hunting and the conservation of biodiversity, which appears when hunting is nonsustainable and intensive and, particularly, when predators are subjected to illegal killing with the purpose of maximising game numbers. Predators (including raptors) are perceived within a large part of the hunting sector as an important limiting factor for small game populations, and thus as an enemy of hunters, in some cases leading to illegal control of protected species. As a result of such illegal activities, the protectionist 
movement sometimes perceives hunting as a detrimental activity for conservation.

Conflict between the desire to maintain the economic and conservation benefits of gamebird shooting and the legal requirements and aesthetic appeal of conserving raptors is manifest across Europe (Manosa 2002; Stroud 2003). In the UK, during the nineteenth and twenteenth centuries, as a consequence of persecution, egg-collection and organochlorine pesticide poisoning, most raptor populations suffered dramatic declines, with a number driven to extinction (JNCC 2000). Subsequent recoveries of some species' populations, through reduced persecution, a ban on organochlorine pesticides and protective wildlife legislation, are regarded as a major conservation success (JNCC 2000; Greenwood et al. 2003). The existence, however, of contemporary healthy and in some cases abundant raptor populations, such as the buzzard, has intensified conflict between conservationists and other stakeholders that utilise prey species.

For wild avian prey, the existence of high levels of predation may not be sufficient to demonstrate that predation is imposing a detrimental impact at the population level (Newton 1998; Park et al. 2005; Gibbons et al. 2007). Predators may be taking similar numbers of birds that may have died from other causes anyway (Errington 1956; Newton 1993; Newton et al. 1997). In addition, many species have evolved to cope with high levels of predation (Stoate and Thomson 1999; Gibbons et al. 2007). For populations of wild birds, the effect of predation may be a reduction in postbreeding numbers, but without a subsequent reduction in the numbers of breeding birds in the following year, then predation cannot be considered to be having a detrimental impact at the population level (Newton 1993).

For gamebirds, particularly released gamebirds, however, the situation is different. For game managers, the important aspect is the depletion of pre-harvest population (Newton 1993; Cote and Sutherland 1995), as this will determine the economic impact of predation on hunting activity (Manosa 2002). Predation of young pheasants Phasianus colchicus placed into release pens during the summer, therefore, is often construed as a detrimental impact on the shoot. In addition to direct predation, gamekeepers claim indirect effects of bird of prey activity, including deaths from 'smothering' that are said to occur when pheasants mass within an enclosure in response to perceived danger and through greater susceptibility to disease through increased stress (Lloyd 1976a; Harradine et al. 1997). In respect to disease, studies have shown an association between elevated parasite load and increased predation in gamebirds (Hudson et al. 1992; Millan et al. 2002; Isomuru et al. 2008).

Across Europe, the common buzzard Buteo buteo is considered to have one of the greatest impacts on game hunting, second only to goshawks Accipiter gentilis (Kenward 2002). In the UK, the population has shown substantial increases, including an eastward range expansion, and has become the most abundant diurnal raptor in Britain (Clements 2000, 2002). The British Trust for Ornithology's Breeding Bird Survey reports regional 'short-term' trends in populations of buzzard between 1995 and 2011: UK $+80 \%$, England + $167 \% *$, Scotland $+31 \% *$, Wales $+4 \%$ (*statistically significant; Risely et al. 2013; BTO/JNCC/RSPB). The longer-term (1970-2011) population trend has been estimated as $+452 \% *$ (Eaton et al. 2013).

In the UK, the conflict between buzzards and pheasant shoots has become especially pronounced with the use of pheasant rearing pens and the density of released pheasants order/s of magnitude greater than anywhere else in Europe (Mustin et al. 2011). The release of pheasants began in response to a decline in traditional shooting of grey partridge Perdix perdix as a consequence of agricultural intensification in the 1950s and 1960s that led to a reduction in wild stocks (GWCT). Since then, there has been an ongoing demand for the release of increasing numbers of pheasants. The National Gamebag Census index of released pheasants increased ninefold between 1961 and 2011, an average increase of $2 \%$ per annum over the last two decades. An estimated 35 million pheasants were released in 2004 (PACEC; Bicknell et al. 2010). Despite the increase in number of pheasants released, the proportion of birds shot has declined since about 1990 (Bicknell et al. 2010). Reasons for this are unclear, but may include higher mortality due to increased predation or disease, habitat changes that may have facilitated greater dispersal or increased difficulty in flushing birds during shoots (Bicknell et al. 2010). Due to the ongoing incremental losses of pheasants throughout the shooting season, due to all causes of mortality, disproportionately large number of birds need to be released to ensure good late season bags (GWCT).

The significant increase in numbers and range expansion of buzzards juxtaposed with the unique magnitude of rear and release makes the conflict between buzzards and pheasants in and around release pens in the UK the primary European focus for this particular issue. Alongside this conflict, persecution of raptors has been ongoing. For example, annually between 2009 and 2013, buzzards (9-32 birds) were the principal victims of confirmed poisoning events and represented 25-47\% of all wild bird poisoning fatalities (RSPB 2009, 2010, 2011, 2012, 2013).

A wide range of measures are available to mitigate the effects of predation by birds of prey (Lloyd 1976a, b; Kenward 1999; Gibbons et al. 2007; BASC undated; Parrott 2012). Direct measures are deployed against the birds of prey themselves (bird management), whilst indirect measures are deployed against resources that the birds of prey utilise (habitat management and livestock or game management). Each of the categories of bird, habitat and game management contain numerous specific techniques aimed at preventing or reducing detrimental impacts. 
In order to evaluate the cost-effectiveness of any mitigation measure, the cost of implementing the measure has to be considered in respect to the magnitude of the reduction in impacts achieved. For buzzards and pheasant poult stocks, the extent and magnitude of the impacts are not clear. Existing research suggests fox Vulpes vulpes predation has the biggest impact on game poults (Robertson 1988; Turner and Sage 2003). In recent years, however, there has been a small but persistent number of licence applications for lethal control by game managers that claim serious damage is being caused by buzzard predation.

This review examined the issue of buzzards at pheasant release pens in the UK, specifically (i) evidence for the extent and magnitude of serious damage to pheasant poult stocks in and around pens and (ii) evidence regarding which management measures are effective at mitigating the impacts on pheasant stocks during the period of release into pens and the beginning of the shooting season.

\section{Methods}

Information on the impacts and mitigation measures used against buzzards at pheasant pens was obtained through a comprehensive literature search of published and grey literature; references present in sourced material were used to sequentially source further references. Published literature was initially identified using Web of Science and Google Scholar. Internet search engines were used to locate additional, unpublished information. Searches involved various key words and phrases, including buzzard, control, deterrents, pheasant, predation, management and raptor. In addition, organisations and workers engaged in research, management and policy towards raptors were contacted for their experiences of measures used to alleviate predation issues. Although the review focussed on the issue of buzzard predation at pheasant pens, examples of measures to mitigate predation by other birds of prey on various livestock in different settings are included, as certain raptor management techniques have not been deployed against buzzards in the UK (e.g. translocation).

Losses to predation need to be considered in the context of overall losses to all causes. Once released into pens, poults can perish before the start of the shooting season from a number of factors: starvation, exposure, disease, predation, natural causes or accidents. In a study that monitored the fate of radio-tagged birds, $25 \%$ of pheasants died (from all causes) before the start of the shooting season; the return rate (i.e. the percentage of released birds that were subsequently shot) was $37.5 \%$ (Turner and Sage 2003). Similarly, losses to buzzards need to be considered relative to losses to other predators, both avian and mammalian. Consequently, the review encompassed impacts by other UK predators when reported alongside that of buzzards.

\section{Results}

\section{Direct predation}

Buzzards are generalist predators that can utilise a number of different hunting techniques - perching and scanning, soaring and walking or standing on the ground (Cramp 1980). Buzzards consume a wide range of prey, principally small mammals (mainly voles Microtus spp. and rabbits Oryctolagus cuniculus) but also birds, amphibians, reptiles and invertebrates (Graham et al. 1995; Swan and Etheridge 1995; Reif et al. 2001; Sim et al. 2001; Zuberogoitta et al. 2006; Selas et al. 2007; Tornberg and Reif 2007; Swan 2011). As generalists, buzzards are able to adapt the composition of their diet to prey availability. In Fennoscandia, the main prey are voles with the most important alternative prey being water voles, shrews, forest grouse and hares (Reif et al. 2001; Valkama et al. 2005). This contrasts with the UK, where the most important component of the diet is rabbit with alternative prey of voles and birds more important in areas with low lagomorph abundance (Graham et al. 1995; Swan and Etheridge 1995). In a review of predation by birds of prey and gamebirds, the proportion of prey items that were gamebirds ranged from 2.6 to $15.1 \%$ in the UK and $<0.1$ to $7.4 \%$ for other European countries (Valkama et al. 2005). A more recent UK study recorded $5.3 \%$ gamebirds (Swan 2011). Any method of assessing raptor diet has potential bias - studies of prey remains (as here) can overestimate the importance of large prey which is more easily found than the remains of smaller prey (Graham et al. 1995; Redpath et al. 2001b).

In respect to evidence of predation by buzzards (and other raptors) on gamebirds in and around pheasant release pens, there has been only a very limited number of empirical studies in the UK (Table 1). The principal birds of prey involved were tawny owls Strix aluco, sparrowhawks Accipiter nisus and buzzards (Lloyd 1976a; Harradine et al. 1997). Lloyd (1976a) (1973-75) estimated the extent of raptor predation from three sources: a survey of estates (154 estates over 2 years), the National Game Marking Scheme (NGMS) and case studies. Nationally, it was considered that $90 \%$ of shoots lost $<1 \%$ of released birds and only one shoot in $30(3.3 \%)$ lost $>5 \%$.

A questionnaire survey of gamekeepers indicated that $61 \%$ (of almost 1000 respondents) reported problems caused by raptor predation (Harradine et al. 1997). Quantification of the losses of poults was possible for some of the estates, with mean losses of released birds of under $5 \%$ and often under $1 \%$. Estimated mean losses to individual species were as follows: buzzard $3.2 \%$, sparrowhawk $1.9 \%$ and tawny owl $1.8 \%$. At some shoots, losses were higher at over $10 \%$. Alongside the increase in the buzzard population, gamekeeper perceptions of impacts has also increased - a more recent questionnaire survey reported that $76 \%$ of gamekeepers 


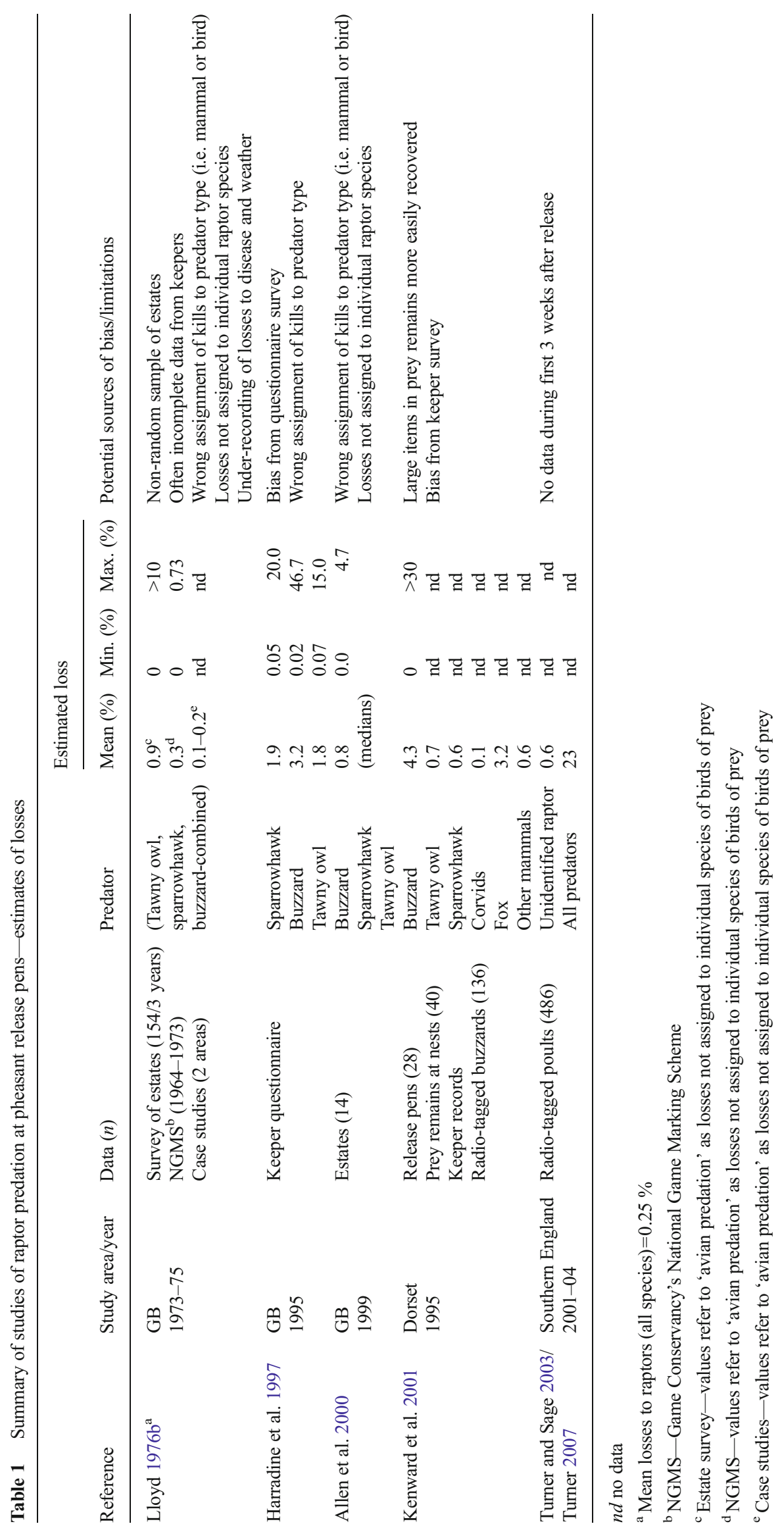


perceived that buzzards imposed negative effects on game (980 respondents) (GWCT 2011).

Gamekeeper records were used to assess levels of predation across 28 pens during 1994-95, after buzzards had re-colonised to a density of two per square kilometre (Kenward et al. 2000). Over 2 years, gamekeepers estimated $9.5 \%$ of released pheasants were killed by the following predators: buzzards $4.3 \%$, tawny owls $0.7 \%$, sparrowhawks $0.6 \%$, corvids $0.1 \%$, foxes $3.2 \%$ and other mammals $0.6 \%$. There was considerable variation in the estimated number of buzzard kills across 55 releases: no pheasants were killed on 9 occasions $(16 \%)$ and $<20$ kills in 23 releases $(42 \%)$. Only $21 \%$ of releases had $>2$ pheasant kills per week. There were some cases, however, where kills were higher: 35-40 pheasants in 12 (22\%) releases, including two occasions when losses exceeded $20 \%$ of the released birds. In observations of 40 buzzard nests, fresh pheasant remains were found in six of the 91 nest-visits (7\%), representing $15 \%$ of the 40 nests. Pheasant comprised only $2.6 \%$ of the 233 prey items at nests; the dominant prey item was rabbit.

Allen et al. (2000) used data from counts and examination of carcasses by gamekeepers to estimate losses of poults and to identify the type of predator responsible (mammal or bird) (28 pens over 14 estates). Using what the authors considered to be the most realistic of three estimation methods, the median loss of released poults was $0.8 \% ; 17$ pens had $\leq 1 \%$ poults lost to avian predators and only 6 pens had losses of over $2 \%$.

Perhaps the most intensive research on released pheasant mortality comes from a radio-tagging study (2001-04) that investigated the mortality of released pheasants at six large rearing estates in southern England (Turner and Sage 2003; Turner 2007). In each of six release pens, 24-30 birds were fitted with radio-tags (out of between 400 and 2000 birds per pen). Of 325 radio-tagged birds, 255 were lost between release in July/August and the start of shooting in late October/early November. At the end of shooting, $16 \%$ of birds still survived. Of the tagged birds, $23 \%$ were predated or scavenged before shooting began - the great majority by foxes. A further $13 \%$ were predated or scavenged during the shooting season (some of which may have been shot but not picked up). Of a total 486 radio-tagged birds, it was believed that three $(0.6 \%)$ were killed by raptors. The study found that steady losses of birds occurred between releasing and shooting with the extent of mortality varying greatly between release pens. The average on-estate shooting return from pens was $30.5 \%$ (37.5\% if including off-estate returns).

Factors influencing predation rates

A number of factors associated with the rate of poult predation were identified in the above studies (Table 2):

Poult age Predation declined as the age of poults at release increased; most kills occurred when poults were aged between
6 and 9 weeks (Lloyd 1976a). Sparrowhawks were reported killing poults up to 12 weeks old, tawny owls up to 12.5 weeks and buzzards up to 14 weeks. It was considered that in addition to larger, older birds being less vulnerable to predators than younger, smaller birds, that age-associated changes in roosting behaviour may also have an effect.

Timing of release Releases in June and July had twice the predation rate of releases in August and September (Lloyd 1976a); survival to the start of the shooting season increased with delayed release dates (Turner and Sage 2003; Turner 2007).

Size of release The proportion of releases predated increased with the size of the release; releases of over 500 birds were predated more frequently than smaller releases (Lloyd 1976a).

Poult density Density had no effect on avian predation in releases of $<500$ birds but in larger releases, high densities increased predation (Lloyd 1976a). Turner and Sage (2003) found no relationship between survival of radio-tagged birds and stocking density, but the proportion of the cohort that was shot was significantly reduced as stocking density increased.

Vegetation Lloyd (1976a) found that release pens with $>20 \%$ cover of shrub layer were predated less than pens with $<20 \%$ cover; pens with at least $60 \%$ cover of herbs or brambles were predated half as much as pens with more open herb layers and pens without either shrub or herb layer were very susceptible to predation. Of the two, the herb layer was considered to be the most important. Allen et al. (2000) found that levels of raptor predation were related to the density of vegetation at a height of $1.5 \mathrm{~m}$ above ground. Kenward et al. (2001) found that buzzards tended not to kill pheasants in pens with aboveaverage shrub cover, or below average deciduous canopy. The number of pheasant killed was greatest in large pens with extensive cover of open ground.

Size of wood Releases in woods $>50$ acres in size were more susceptible to predation than those in smaller woods (Lloyd 1976a). Pens extending out of a wood were more liable to large losses and mass kills than those completely within the wood.

\section{Buzzard behaviour}

Kenward et al. (2001) radio-tracked 136 buzzards to obtain data on their presence at 28 pheasant release pens. Thirty-six buzzards were recorded at pens (i.e. $<200 \mathrm{~m}$ from pen), most often at those with open, deciduous canopies. Pens were most likely to be visited by buzzards that had fledged nearby, but the proximity of nests had little influence on how much predation occurred. Despite $44 \%$ of buzzards having a pheasant 


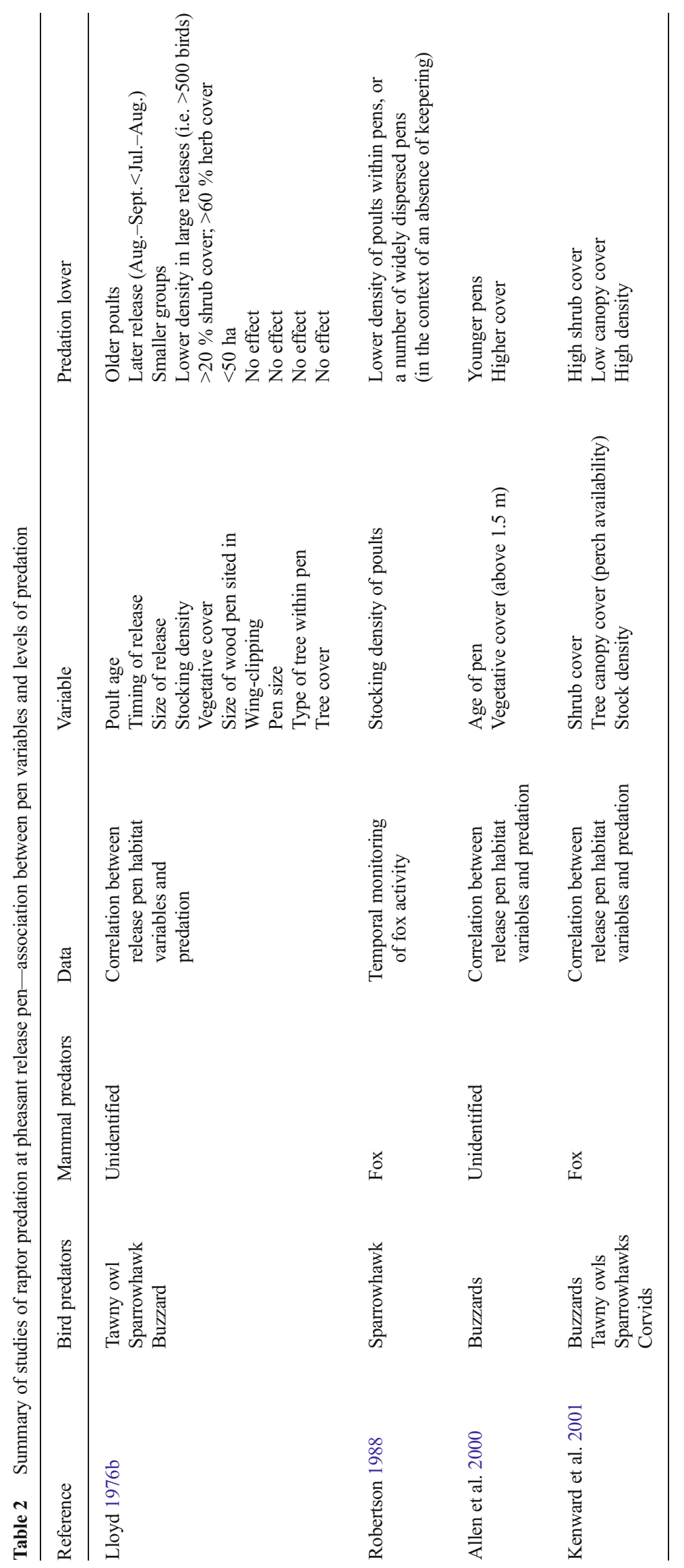


pen within their home range, only $8 \%$ (11 birds) recorded an appreciable association with a pen. These 11 birds formed two distinct categories as follows: eight buzzards with less than $20 \%$ of their locations at pens and three buzzards with at least $50 \%$ of their locations at pens.

\section{Indirect effects}

Gamekeepers' perceive that, in addition to direct predation, raptor attacks have indirect effects on the remaining birds, including reluctance to leave cover to feed, resulting in depressed growth and poor condition; reluctance to come to roost; widespread dispersal outside the pen; roosting birds flying to ground exposing them to mammal predators if outside the pen and 'smothering' events as a result of poults massing as a result of panic induced by the presence of a bird of prey (Lloyd 1976a; Harradine et al. 1997).

Following observations at release pens, however, Lloyd (1976a) concluded that although the effect of disturbance by birds of prey could not be quantified, the importance of any effects was probably overestimated. For example, sparrowhawk flights through a release pen revealed minimal effects on the poults - birds froze momentarily then resumed feeding when the sparrowhawk had disappeared. In a subsequent study, no relationship was found between the frequency with which raptors occurred at release pens and losses to causes other than direct raptor predation (Allen et al. 2000). The study suggested, however, that although not substantiated in the analysis, such indirect losses may only become apparent under exceptional predation levels. Also, that some indirect effects may be non-lethal for which the study was not designed to detect.

\section{Mitigation measures}

A wide range of avian management techniques have been used in attempts to alleviate predation by raptors and other birds of prey on livestock around the world, including at pheasant release pens in the UK (Table 3).

\section{Deterrents (visual and auditory)}

A British Association for Shooting and Conservation (BASC) survey revealed that most (c.84\%), but not all, gamekeepers affected by raptors took some form of preventive measure (Harradine et al. 1997). Many different deterrent and scaring techniques were used, either in isolation or combined, e.g. bangers, gas guns, alarms, hangers (i.e. loose items suspended above the pen) and mobiles, lights, mirrors, radios, owl decoys, scarecrows and human presence. The survey concluded that the '...most widely used scaring measures are reported to have varying and generally low levels of success...' and '...with little apparent benefit...' Estimated values from graphs presented in Harradine et al. (1997), however, indicated that for some species, over half of gamekeepers reported at least partial success in the use of scaring devices: buzzard $(n=129)=51 \%$, tawny owl $(n=160)=61 \%$, sparrowhawk $(n=184)=41 \%$, and goshawk $(n=43)=37 \%$.

Reflective tape, silver foil, hanging bags and lights and mirrors have all shown some level of deterrent effect under some circumstances (Lloyd 1976a; Harradine et al. 1997; Allen et al. 2000). The Raptor Working Group (JNCC 2000), however, concluded that there was no consistent application of deterrents at pheasant release pens; some of the most commonly used were those which appeared least successful, whilst some of the apparently most successful were less frequently used.

\section{Field trials of deterrents}

Lloyd (1976a) reported a number of opportunistic experiments using flashing lights, and 'glitterbang' (foil strips) in which their placement at pens was followed by a cessation or extended break in raptor activity and/or kills. Other reported experiments in Europe had shown large silvered balls were effective in protecting reared game and chickens from diurnal raptors, particularly sparrowhawks and goshawks (Mansfield 1954 and Pfeiffer and Keil 1963 reported in Lloyd 1976a).

Allen et al. (2000) evaluated hanging bags, lights and mirrors and mylar tape. Predation levels were lower in all three categories of deterrent pens in comparison to control pens. All three deterrents provided a cost-effective means of minimising raptor predation - relative to a mean loss of $5 \%$ poults per pen (1000 birds stocked per pen) (Allen et al. 2000). Due to variation in recording by gamekeepers at different pens, however, the results were considered provisional. Allen (2001) repeated the field-experiment but with data collected solely by a dedicated field-team. Relative to control pens, the rate of predation on mylar pens was $45-73 \%$ lower. Due to low sample sizes, it was recommended that further trials should be undertaken.

\section{Diversionary feeding}

In Ireland, Lloyd (1976a) reported the successful use of dead pigeons to prevent sparrowhawk predation on pheasant poults at a release pen. A questionnaire survey of gamekeepers reported '...some measure of success...' when using diversionary feeding in combination with scarers and pen protection (Harradine et al. 1997). In Scotland, in recent years, a small number of gamekeepers have reported that diversionary feeding had been effective in reducing buzzard predation at pheasant release pens (Science and Advice for Scottish Agriculture SASA, pers comm). 


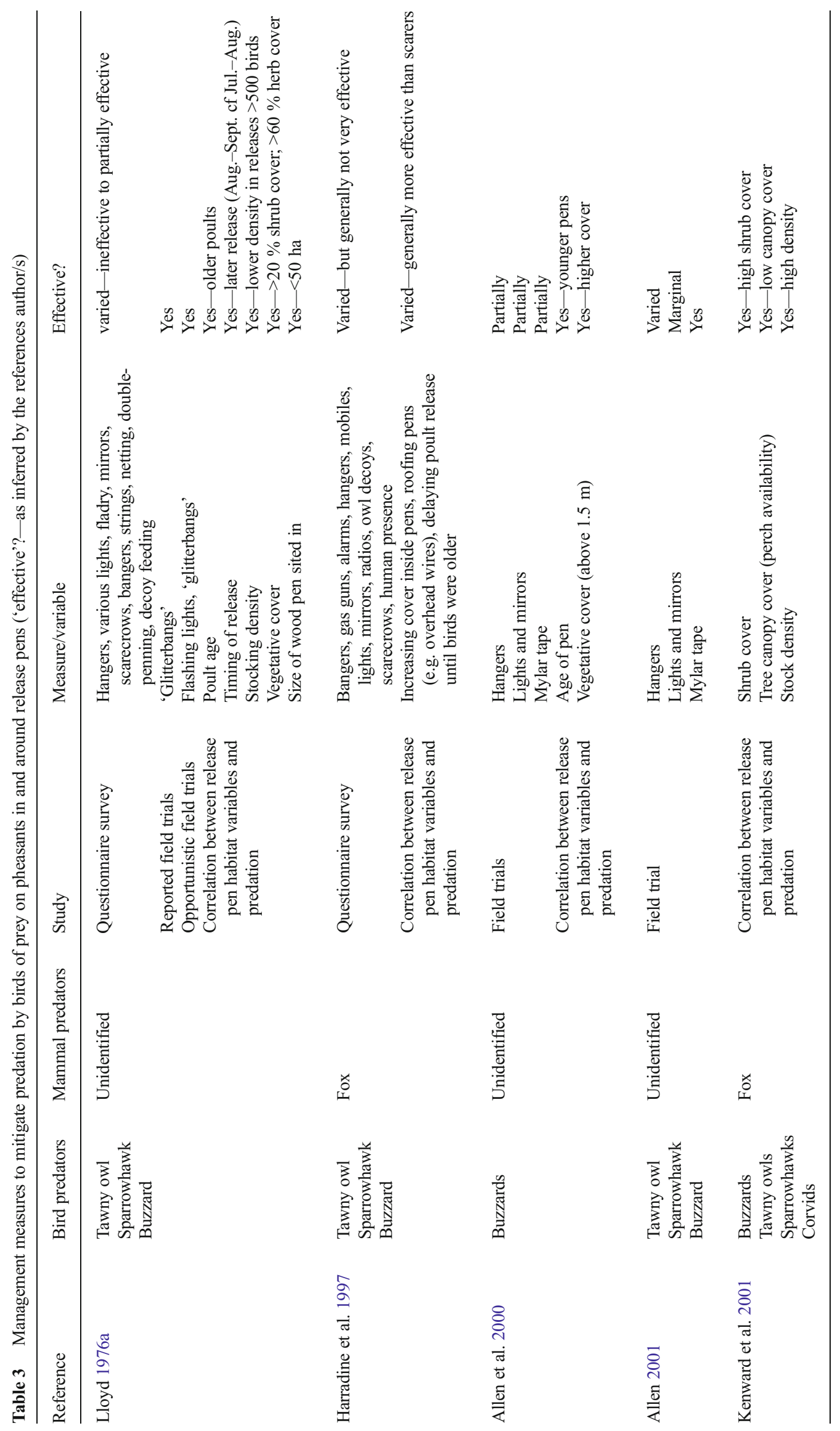


In other circumstances, in England, the predation rate in a colony of little terns Sterna albifrons, decreased when the two pairs of resident kestrels Falco tinnunculus were provided with supplementary prey (Durdin 1993). However, supplementary feeding of peregrines Falco peregrinus had little success during attempts to protect a roseate tern Sterna dougallii colony (Avery and Winder 1990). In Scotland, supplementary feeding of hen harriers Circus cyaneus, greatly reduced the number of grouse chicks taken by fed birds compared to unfed birds; reduced predation, however, was not followed by increased autumn density of grouse; harriers also continued to predate adult grouse (Redpath et al. 2001a). On Mull, recommendations to reduce white-tailed eagle Haliaeetus albicilla predation on lambs included the use of feeding sites in late winter to encourage eagles to nest as remote as possible from lambing areas (Marquiss et al. 2003b).

\section{Exclusion}

Lloyd (1976a) found that on some estates, strings were crisscrossed over the top of the pen (sometimes threaded with reflectors). On other estates, netting was put right over the pen or birds were released into a small covered pen within the release pen to acclimatise them.

Harradine et al. (1997) reported that pen protection (i.e. using overhead netting, wires, tapes and fishing line) appeared to offer a means of excluding raptors from release pens. Data presented indicated that $83 \%$ of gamekeepers $(n=36)$ considered pen protection measures to be at least partly successful. These measures, however, were not used frequently due to the cost and practicality associated with the size of the pens, and the requirement to allow pheasants to leave the pen via the top as they mature.

In Scotland, there has been the reported use of a release pen in which one half was fully enclosed with a mesh roof (SASA pers comm). Poults were herded/encouraged into the enclosed section for the night and out again into the open-section in the morning. Although it was not possible to manage every individual poult in this way, a significant proportion of the stock spent the nights in the fully-predator proof enclosure.

Barrier methods have also involved the suspension of reflective tape (a visual deterrent in addition to a physical barrier) across identified raptor flightlines to interfere with attacks on poults.

\section{Habitat management}

Studies have consistently reported lower predation rates in pens with good vegetative cover of shrub (>20\%) and herb (>60\%) and below average cover of deciduous canopy (Lloyd 1976a; Allen 2001; Kenward et al. 2001).

Effective outcomes of habitat manipulation have been reported in Scotland in recent years, inside release pens, at feed stations and in the open environment (SASA pers comm). Inside pens, cover has been provided in the form of brash piles presented both in 'natural' heaps of cut conifers and in the form of 'wigwam' or tented structures. At feed stations, cover has been provided with camouflage netting. Whilst in open fields, 'hides' constructed from wooden pallets and straw have been provided as refuges, or bolt-holes.

In the poultry industry in the USA, to reduce the probability of 'smothering' events in outside pens as a result of birds piling up when frightened, it is advocated that all rightangled corners in pens are eliminated (Bourne 2001).

\section{Livestock management}

Supplementary stocking Allen et al. (2000) found that for the majority of pens, the estimated losses to raptors was $\leq 1 \%$ of released birds, equating to 10 birds in a pen holding the median stock of 1000 poults; the estates in the study released on average around 9000 birds. The additional cost of rearing 90 supplementary birds to compensate for anticipated losses was exceeded by the income from the return of the supplementary birds (based on a return rate of $40 \%$, Tapper 1992). Extrapolating to the occasional higher rates of loss experienced at some pens, the supplementary income still exceeded the additional rearing costs. However, a number of difficulties were recognised. Compensating for potentially unexpectedly high losses is problematic as their occurrence and magnitude cannot be predicted with any certainty (Allen et al. 2000). Also, raising significant numbers of supplementary birds raises issue such as capital outlay and overstocking.

Stocking density The Game Conservancy Trust (2006a, b) and The Code of Good Shooting Practice (2008) recommended that: '...to avoid damage to habitat in most situations shoots should avoid releasing more than 1000 pheasants per hectare of pen, and more than 700 per hectare of pen in ancient, semi-natural woodland...'. Historically, however, studies have recorded stocking densities above recommended levels, sometimes far in excess. Lloyd (1976a) reported that approximately two thirds of releases were in pens smaller than recommended; in large releases, the frequency of predation increased with high density. It was considered that the effect of density may be due to inadequate cover for all birds to escape into, and possibly to the actual destruction of the ground cover by the birds themselves. Allen et al. (2000) reported a median stocking density of 1500 poults per hectare (28 pens over 14 estates), whilst Allen (2001) recorded densities for two estates of 2570-3500 and 3750-4000 poults per hectare, respectively. The Game Conservancy and Wildlife Trust reported a 1988 study of 43 release pens in which the average stocking density was 2250 pheasants per hectare (Sage et al. 2005). The same reference also cited unpublished data from a more recent (2004) study that showed a mean 
stocking density of 1800 birds per hectare for a sample of 53 pens from the same area.

\section{Current practical guidelines for pheasant release pens}

The BASC, drawing on these findings, published practical guidelines for game managers and keepers to alleviate predation by birds of prey at release pens (http://www.basc.org.uk). The recommendations advocate the following: (i) ensuring the appropriate vegeatative cover; (ii) reducing the availability of potential raptor perches; (iii) releasing supplementary poults; (iv) releasing older poults (7-8 weeks); (v) suspending reflective tape over open areas; (vi) deploying, vary and move scaring devices; (vii) leave kills in pens for returning raptors to reduce the risk of fresh kills and (viii) providing diversionary food away from the pen.

\section{Translocation}

A number of reviews concerning the capture and removal or translocation of raptors have been published (Linnell et al. 1997; Cade 1986, 2000; Fischer and Lindenmeyer 2000). The general consensus was that whilst translocation can be an effective tool for conservation, particularly with regard to re-introduction, capture and removal to resolve humanwildlife conflicts has mostly been unsuccessful.

In the USA, translocation of black vultures Coragyps atratus (Avery and Cummings 2004) and golden eagles Aquila chrysaetos (Phillips et al. 1991; Linnell et al. 1997) proved largely ineffective. Some eagles returned from up to $400 \mathrm{~km}$ away and vacant territories were taken over by nonterritorial birds within a mean of 3 days; problems with vultures did not decrease at trap sites and also increased at release sites. In South Africa, five of eight translocated black eagles Aquila verreauxii, crowned eagles Stephanoetus coronatus and martial eagles Polemaetus bellicosus returned from distances between 28 and $105 \mathrm{~km}$ (Boshoff and Vernon 1988 reported in Linnell et al. 1997). In Scotland, removal experiments showed that around half of territory-holding sparrowhawks removed were replaced between 12 and 28 days later (Newton and Marquiss 1991).

In contrast, in Sweden, the relocation of goshawks has had some success (Kenward 2002). The use of spring-nets on pheasant kills permitted the selective capture of juvenile birds ( $80 \%$ of the total birds captured) that were responsible for the killing. Few birds returned after being translocated more than $30 \mathrm{~km}$ (Marcstrom and Kenward 1981). It was recognised, however, that as most hawks removed were juveniles, their non-return may have been due to their unfamiliarity with the areas. More wide-ranging species may require much greater translocation distances (Kenward 2002). In South Dakota, USA, the translocation of 19 sub-adult golden eagles ( $>322 \mathrm{~km}$ from the capture site) did reduce predation on farms at the capture sites (Waite and Phillips 1994) but the long-term affect was not reported.

Nest and egg destruction

In the UK, under the Wildlife and Countryside Act (1981), licences can be issued to take a small number of birds of prey for the purpose of preventing serious damage. Over recent years, there has been a small but persistent number of applications for licences to kill buzzards made to Natural England by gamebird and poultry interests. Prior to 2013, there had been no licences granted in respect to buzzards or any other raptor for this purpose.

In 2013, however, Natural England issued the first ever licences for the destruction of nests and eggs and for the removal of buzzards (see below) to protect game and poultry interests, respectively. The first case involved a pheasant shoot, with licences permitting the destruction of up to two buzzard nests (and eggs) across each of two release sites. Following implementation, the licensee reported no benefit as the buzzards merely re-nested less than $100 \mathrm{~m}$ from the original site (Natural England pers comm).

\section{Removal of adults}

In the second case of licensing in England, a permit was issued to a free-range laying poultry business which allowed the permanent removal of up to three buzzards. Subsequently, two birds were live-captured (one juvenile and later one adult) and placed into captivity with experienced falconers. The poultry farm reported no losses to buzzards following the removal of the adult (which hunted pigeons and rabbits for a falconer) - undertaken almost a year earlier (Natural England pers comm).

Lethal

In the USA, selective lethal removal of specific problem vultures was considered as potentially contributing to resolving local vulture management conflicts (Avery and Cummings 2004). Federal and state laws protect all hawks and owls. However, the United States Fish and Wildlife Service (USFWS) may issue shooting permits for problem hawks and owls if non-lethal methods of controlling damage have failed or are impractical and if it is considered that killing the offending birds will alleviate the problem (Wade et al. 1984; Wade 1986; Hygnstrom and Craven 2005).

The EU Concerted Action Reconciling Gamebird Hunting and Biodiversity (REGHAB) project concluded that very little is known about the effect of culling on raptor populations (Vinuela and Arroyo 2002). It was also concluded, however, that in some countries, there is a need for efficient and selective methods of legal predator control, to replace invasive, 
non-selective and illegal methods commonly used (particularly poison).

\section{Discussion}

Extent and magnitude of impacts

Historically, losses of pheasant poults in and around release pens to raptor predation have been low, commonly $\leq 1 \%$ of birds released into pens where predation occurs, although a small number of shoots did suffer higher losses (Lloyd 1976a; Harradine et al. 1997; Allen et al. 2000). Losses to raptors represented a small percentage of losses relative to total losses to all causes of mortality (e.g. predation, disease, weather, cannibalism); before the start of the shooting season, typically $25 \%$ of birds released are lost to all causes (e.g. Turner and Sage 2003). For the great majority of shoots, far more pheasants were lost to other causes in the period outside the release pen, than the 1-2\% losses to birds of prey inside the pen (Lloyd 1976a; BASC undated). It was recommended that efforts to minimise these losses to other causes would have much greater benefit.

Losses to raptors, however, can often be overestimated compared to other sources of loss, influenced by the different behaviour of raptors relative to other predators (Lloyd 1976a; Allen et al. 2000). Raptor activity, particularly diurnal species such as buzzard and sparrowhawk, in and around release pens is very noticeable with the subsequent discovery of killed poults often attributed to the observed raptor. In France, a detailed field study to quantify losses of free-range poultry to predators contradicted farmers' belief that raptors and corvids had a major impact on poultry (Stahl et al. 2002). Farmers' overestimation of losses to avian predators was considered due to their being more likely to attack during the day, perching in the area, rarely removing prey from the site and eating prey in situ. In the UK, Allen et al. (2000) found no significant relationship between the estimated avian predation levels and the frequency of raptor occurrence as recorded by gamekeepers at release pens. In contrast, mammalian predators are generally active at night and may be more likely to remove killed birds. Similarly, the nocturnal tawny owl is perceived by fewer gamekeepers (49 \%) to impose detrimental effects compared to the more conspicuous buzzard (76\%), sparrowhawk (73\%) and goshawk (70\%) (GWCT 2011).

A number of factors were associated with the level of predation, which was lower (i) with increased age of poults at release, (ii) in August-September releases compared to releases in June-July, (iii) in pens with good vegetative cover, (iv) in pens within woods $<50$ acres and (v) in releases of $<500$ birds (Lloyd 1976a; Allen et al. 2000; Kenward et al. 2001). Whilst there was no simple relationship between density and survival (Turner and Sage 2003; Turner 2007), there were indications that predation rates were greater in high density releases (Lloyd 1976a; Kenward et al. 2001).

Evidence is not available to determine whether individual 'problem' buzzards can be implicated in predation events at pheasant pens. One study has shown that only a minority of buzzards frequented release pens but the data did not permit the investigation of links between buzzard presence and predation records (Kenward et al. 2001). More recently, however, at a poultry farm, the licensed removal of one adult buzzard was followed by a cessation in predation events that had previously persisted for around 18 months (Natural England pers comm). For a number of other predator species, studies have shown that predation events on livestock can be unevenly distributed across the predator population, with a small number of individuals responsible for a significant majority of total kills (Eurasian lynx Lynx lynx, Stahl et al. 2001; white-tailed eagle, Marquiss et al. 2003a; jaguar Panther onca, RosasRosas et al. 2008).

In terms of indirect losses, although no evidence for significant effects of raptor activity have been found (Lloyd 1976a; Allen et al. 2000), the appropriate physiological studies have not been undertaken. The relationship between acute stress events (e.g. predator activity) and chronic baseline stress imposed on poults by other factors, such as stocking levels (recommended and over-stocking) and competition for resources, such as food, water, warmth and cover and their relative and/or additive effects on physiology, health and mortality are not known.

It is important to note that the most recent empirical studies on levels of impact were completed around 20 years ago (Kenward et al. 2001), and in some cases over 35 years ago (Lloyd 1976a). Over the ensuing period, the populations of common birds of prey have undergone various changes in numbers and range; for buzzard, significant population growth and range expansion has occurred (Clements 2000, 2002). Investigations of the extent and magnitude of the impacts of buzzards and other birds of prey at release pens have not been undertaken widely in the context of the current status of raptor populations.

\section{Mitigation}

Although a wide range of techniques have been used in attempts to mitigate predation by raptors at pheasant release pens, there is very little empirical data to permit an evaluation of their effectiveness. Rather, 'evidence' for their efficacy, or not, has been generally descriptive and anecdotal. The few experimental trials undertaken (e.g. Lloyd 1976a; Allen et al. 2000; Allen 2001) have been limited in their robustness being either opportunistic one-off trials, having few replicates or confounded by other factors. 


\section{Non-invasive techniques}

Traditional visual and auditory scaring techniques have been deployed relatively frequently against raptors, with varying degrees of deterrence and duration of their effectiveness being reported. All visual and auditory deterrents, used on their own, will gradually become less effective due to habituation (Inglis 1985; Bomford and O’Brien 1990). To maximise effectiveness, through prolonging habituation, deterrents should be as realistic as possible, be temporally and spatially unpredictable, present as real a threat as possible, be presented as infrequently as possible and be reinforced or replaced with alternative types of devices. Deterrents should be deployed as soon as predation occurs, i.e. before a pattern of raptor attendance is established; once a pattern is established deterrence will be more difficult.

Diversionary feeding has had some success in reducing buzzard and sparrowhawk predation at pheasant pens (Lloyd 1976a; Harradine et al. 1997; SASA pers. comm.). The technique has also been suggested as a possible mitigation method to reduce red grouse Lagopus lagopus predation by hen harriers on UK grouse moors (Thirgood and Redpath 2008). Supplementary feeding of hen harriers reduced the number of grouse chicks taken by fed birds compared to unfed birds (Redpath et al. 2001a). Subsequently, diversionary feeding scored highly amongst both grouse managers and raptor conservationists when evaluating a range of hen harrier management options (Redpath et al. 2004).

A number of concerns are associated with diversionary feeding, however, such as increasing juvenile survival (and hence population size), the risk of attracting additional birds of prey into the area, legal issues with the provision of carcasses generally and carcasses containing lead shot. All of these can be addressed with careful consideration (Natural England guidance). Diversionary feeding only needs to be deployed for the relatively short poult maturation period, with the food targeted at the individual birds of prey active within the vicinity of the pen. Supplied carcasses can be whole, freshly shot specimens of natural prey, such as rabbits, woodpigeons Columba palumbus or corvids Corvus spp., killed using non-lead shot. Carcasses should be supplied off the ground and unconsumed carcasses removed.

Total exclusion techniques (overhead netting, fishing line, wires and tape) although generally considered to be beneficial, pose practicality and husbandry concerns (Harradine et al. 1997). Partial exclusion methods that have incorporated smaller acclimitisation pens within the larger release pens and release pens divided into separate enclosed (night-time) and open sections (day-time) may mitigate concerns around allowing pheasants to leave the pen via the top as they mature.

One of the principal factors identified as reducing raptor predation was the presence of sufficient vegetative cover in the form of herb and shrub layers (Lloyd 1976a; Kenward 1999;
Allen 2001; Kenward et al. 2001). Pheasants prefer shrubby areas: winter pheasant density within-site was positively influenced by the presence of a high proportion of shrubby cover (100-200 cm) (Robertson et al. 1993a) and breeding density within-site was related to the availability of woodland edges with high levels of shrubby cover $(30-200 \mathrm{~cm})$ (Robertson et al. 1993b). Although adequate cover of both herb and shrub layers was associated with lower predation rates, Lloyd (1976a) considered the herb layer to be the most important. Adequate suitable cover within pens is essential to allow poults to develop their natural anti-predator behaviour and also provides protection by screening and/or physically protecting the birds. It has not been uncommon, however, for release pens to be stocked above recommended levels (Lloyd 1976a; Allen et al. 2000; Sage et al. 2005) with detrimental consequences for the retention of sufficient vegetation. It is recognised that the release of large numbers of pheasants into a pen over a long period can lead to changes in the ground flora in some instances up to $15 \mathrm{~m}$ around the pen (Game Conservancy Trust 2003; Sage et al. 2005).

Creative solutions in the provision of supplementary cover have been effectively implemented in individual cases, including brash structures within pens, and timber or 'tented' 'refuges' in the wider habitat outside, to protect pheasants at feed stations or during transit in open habitat. The provision of supplementary cover, however, is unlikely to compensate in extreme cases where pens are sited in unsuitable locations with respect to the appropriate mixture and extent of natural vegetation types. It is important, therefore, to site pens in appropriate locations in the first instance and in circumstances where continued problems occur where pens are short of cover to relocate them to sites with more suitable habitat.

A recurring theme in the mitigation of raptor-livestock conflicts is the modification of livestock management. For pheasants, the size of pens and the stocking density of poults may influence survival rates (Lloyd 1976a; Kenward et al. 2001; Turner and Sage 2003). Large pens minimise mass kills by mammalian predators, feather picking, the build up of disease and impact on ground flora (Carroll and Robertson 1997). Over-stocking has the potential to impact detrimentally on the quality of the vegetative cover, levels of stress and disease transmission. It has been suggested that desired bags could be achieved if pens were stocked at lower density but with an increased number of pens. However, this would increase costs and the area where pens impact on woodland vegetation. Releasing older poults and releases later in the season are associated with lower levels of raptor predation. Addressing the issue of later releases, however, is not necessarily straightforward. For example, the longer that chicks are kept in small cages on the rearing field, prior to introduction into release pens, the greater is the chance of feather-pecking and the risk of disease (Lloyd 1976a). 
Mitigation of the effects of predation is an ongoing process in which a pro-active and integrated management strategy (IMS) is recommended. In Australia, combinations of scaring devices is advocated to reduce the predation of wedge-tailed eagles on lambs (DEC 2007). In the USA, it is recognised that no single method is $100 \%$ effective and that an IMS that includes both preventive and selective control methods provides the best protection (Franklin and Powell 1994). In the UK, practical guidelines have been published by the BASC advocating combinations of scaring techniques, habitat modification, decoy feeding and husbandry to alleviate raptor predation at pheasant release pens. The extent to which these guidelines are implemented is not known.

In order to derive cost-effective management strategies knowledge about the relative costs of losses to predation and of deploying mitigation measures is necessary. A major gap in knowledge is the lack of empirical data supporting the advocacy of various management techniques. Based on historical predation rates, deterrents and supplementary stocking were considered to be cost-effective (Allen et al. 2000; Allen 2001). As is the case for estimates of raptor predation, however, evaluations of the efficacy and cost-effectiveness of mitigation measures in the context of current raptor populations have not been undertaken.

Invasive techniques

In Britain, a BASC survey indicated that $14 \%$ of gamekeeper respondents wished to see the licensed removal of troublesome raptors and $25 \%$ a cull of raptors (Harradine et al. 1997). The BASC has recommended that an immediately responsive licensing system be put in place for the destruction/ translocation of specific problematic raptors, their nests or eggs, for those situations where serious damage cannot otherwise be prevented (BASC 2009). There are numerous sociopolitical issues associated with any potential deployment of these more invasive measures in the UK.

Translocation of raptors in order to ameliorate wildlife conflict has largely proved to be ineffective in the long-term: birds can return to their former range, other birds can take their place and cause similar conflict, suitable areas for translocation are lacking or the problem is simply moved elsewhere (Linnell et al. 1997; Cade 2000; Fischer and Lindenmeyer 2000). In circumstances considered to be effective, the removal involved juveniles translocated during a period of natural dispersal (goshawks in Sweden, Marcstrom and Kenward 1981). A further issue with translocation involves the potential for detrimental impacts on the welfare of the relocated individuals (Massei et al. 2010).

Although concluded to be largely ineffective, the context in which translocation is deployed is a key consideration. To be effective, a number of conditions need to be met as follows: (i) recognised as a short-term solution, (ii) removed birds are 'problem' individuals, (iii) potential replacements specialise less on the target prey, (iv) removed birds do not return and (v) impacts at the removal site are significantly reduced. In respect to buzzard predation at pheasant release pens, the poult-rearing period is of relatively short duration but information on the other criteria is lacking. There is a paucity of information on return rates of translocated buzzards, replacement periods for alternative individuals or the occurrence of 'problem' individuals specializing in predation of poults.

A number of factors potentially mitigate an effective outcome of buzzard translocation in the UK. The increase in their numbers and range (Clements 2000, 2002), together with the density and distribution of pheasant shoots, will limit opportunities for suitable release sites. A key decision when considering translocation to reduce conflict is whether there is any real benefit in moving individuals of a species that is at carrying capacity in all areas in which there is suitable habitat (Kenward 1999, 2002). In southern Britain, in addition to the breeding population, there is a large non-breeding population; Kenward et al. (2000) estimated only one in every four buzzards was breeding. Buzzards also exhibit strong natal philopatry, either remaining in their natal area during their first winter or returning towards their natal area in the spring (Walls and Kenward 1995; Walls et al. 2004); translocated buzzards, therefore, may exhibit a propensity to return. Young buzzards are dependent on their parents for a period of 6-8 weeks postfledging (Cramp 1980), coinciding with the period when pheasant poults are in release pens.

The potential benefits of removal may depend on evidence that the conflict is caused by a small proportion of birds with specialised behaviour. Although the underlying assumption of the problem-individual paradigm had been little tested (Linnell et al. 1999), more recent studies, on a number of species, have shown that a small proportion of individuals in the predator population can be responsible for the majority of predation events (Stahl et al. 2001; Marquiss et al. 2003a; Rosas-Rosas et al. 2008). The observation that only a small proportion of radio-tagged buzzards associated with pheasant pens (Kenward et al. 2001), together with the anecdotal reporting that the removal of two buzzards from a poultry farm was followed by a cessation of predation, gives some support to this idea. Under some circumstances, therefore, selective removal may have the potential to reduce a conflict by targeting problem individuals without requiring any wider reduction in local population numbers. However, in the case of pheasant release pens, the situation may be more complex, with Kenward et al. (2001, 2002) suggesting that any such specialist buzzard behaviour had the potential to be a function of, or reinforced by, the habitat features of pens. Radio-tagged buzzards associated most with pens that had an open, deciduous canopy, whilst predation was initiated most often at pens with a deciduous canopy. Site attraction, due to the enhanced opportunities for perching (compared to pens without a 
deciduous canopy) may encourage initiation of the exploitation of vulnerable prey (enhanced by low cover). Specialisation on prey, therefore, may involve a complex interaction between inherent or learnt behaviour and its incitement or reinforcement mediated by habitat features. Under this scenario, problem individuals might be managed through pre-emptive pen and habitat management.

In circumstances where the impact of raptor predation is significant and ecological techniques are not effective, it has been argued that consideration should be given to more intrusive techniques, such as the elimination of particular problem individuals (Vinuela and Arroyo 2002). Kenward (1999) raised the point that although the strict protection of raptor populations is an important conservation tool, if treated as an ideology, it also has the potential to promote damaging conflicts and that, if serious predation problems are ignored, respect can be lost for conservation laws, and birds may be killed anyway - but unselectively. In France, for example, despite raptors being fully protected, some hunters culled harriers, in part due to frustration that no legal measures were enacted in response to their demand for control (Bro et al. 2006) .

As is the case for translocation, however, the consequences of such removal are unknown, and so its potential effectiveness cannot be predicted. For example, the rate at which the vacated territories of removed birds may be taken over by alternative buzzards and the behaviour of those replacement birds towards rearing pens and pheasants. The social consequences of removal are also unknown. On the one hand, addressing legitimate concerns might lead to increased compliance with conservation laws, but on the other hand, there is concern that any legal licensing could lead to increased illegal persecution. The removal of buzzards has, in addition, a potential number of wider ecological and agricultural implications. The removal of only selected, larger predator species can allow increases in the populations of smaller predators ('mesopredator release'), which may result in no decrease, or an increase, in overall predation rate (Crooks and Soule 1999). In the same vein, in respect to the control of predators other than raptors, the EU REGHAB project considered that '...little attention has been paid to the indirect potential positive effect that some raptors may have on game populations by preying on, for example, corvids, or displacing other raptor species'... (Vinuela and Arroyo 2002). In a number of recent studies, corvids were the highest avian constituent of buzzard diet, representing $18 \%$ of all prey remains at nest sites in the West Midlands (Sim et al. 2001), $14 \%$ of all prey remains at nest sites in Scotland (Swan 2011) and $20 \%$ in Ireland (Rooney and Montgomery 2013). Consideration of these effects is relevant to landowners whose holdings support wildbreeding populations of gamebirds in addition to pen-reared. The main constituent of buzzard diet, the rabbit, can cause significant agricultural damage. In light of these broader interactions, consideration of the issue as solely a onepredator, one-prey relationship with no wider consideration of trophic interations has been criticised as too simplistic (Lees et al. 2012).

\section{Gaps in knowledge}

In order to further inform the debate on buzzard (and other raptor) predation at pheasant release pens, a number of gaps in knowledge need to be addressed as follows: (i) quantification of direct and indirect losses of poults in the context of current buzzard populations, (ii) the occurrence of 'problem' individual buzzards and the origin of 'problematic' behaviour, (iii) controlled replicated field trials to evaluate the most promising mitigation measures and (iv) comparison of the features of pens and estates claiming to experience high levels of raptor loss with those not experiencing such problems.

Where buzzard predation is occurring, quantification of losses is necessary in order to assess whether the activity imposes a significant cost to game managers. Quantification of predation losses is also necessary in order to evaluate the costeffectiveness of approaches to mitigating the impacts. These gaps in knowledge could be addressed with field studies that undertake a detailed evaluation of the magnitude of direct impacts on pheasant release pens using a combination of techniques, including monitoring and analysing kills at release pens, tracking the movements and activity of marked buzzards relative to pens and monitoring prey delivered to nests. The investigation of indirect impacts could involve monitoring stress parameters (e.g. behaviour, hormones) of pheasants in experimental aviaries or release pens relative to factors directly controlled by experimenters, including stocking density and presence of a predator (e.g. presentation of a trained raptor). Ideally, field trials of mitigation measures would be carried out on a series of shooting estates with different treatments assigned to matched release pens replicated across all estates. For the experiment to have sufficient statistical power, the study would need to focus on release pens that are subject to predation levels at the higher end of the scale of impacts. There is a paucity of field trials that have evaluated the effectiveness of techniques to mitigate raptor predation at release pens, including deterrents, exclusion, habitat manipulation and diversionary feeding. The few experimental trials that have been undertaken (e.g. Lloyd 1976a; Allen et al. 2000; Allen 2001) have been limited in their robustness being either opportunistic one-off trials, having few replicates or confounded by other factors, including variation in recording effort between treatment sites. Finally, comparisons could be made between pens or estates reporting high levels of predation with those experiencing either low or no problems, to identify any consistent factors 
associated with predation levels, including the rearing process, buzzard density and activity and predator management strategy.

\section{Managing conflicts}

The conflict surrounding buzzards and pen-reared pheasants in the UK represents just one of a number of increasing conservation conflicts globally (Redpath et al. 2013). In an exploration of strategies and case studies, Redpath et al. (2013) recognised that the origins of conflicts often go beyond the perceived impact of predators and arise from deeper factors rooted in social and cultural history. Redpath et al. (2013) also recognised two main elements in managing conservation conflicts: passive mapping of the conflict to collate information on evidence and context, and active attempts at conflict management involving stakeholder engagement to explore solutions and develop strategies.

In respect to conflicts between raptor conservation and gamebird hunting across Europe, the implementation of ecological, economic and sociological tools has been advocated (Kenward 2002; Vinuela and Arroyo 2002). Ecological tools include those mitigation measures discussed in the present review, economic tools include, for example, incentive schemes to promote habitat and species conservation, whilst sociological tools involve encouraging cooperation between opposing stakeholders to adopt a concept of consumptive and non-consumptive sustainable use of biodiversity to pay for conservation. The implementation of potential solutions, however, is dependent on their mutual acceptability to the opposing stakeholders.

In respect to stakeholder cooperation, a relatively recent introduction into the debate on the raptor-gamebird conflict is the application of a consensus building approach (Redpath et al. 2004). Consensus building approaches involve techniques that evaluate the acceptability of different management solutions to the conflict by quantifying the perceptions of opposing stakeholders. These approaches involve a wide variety of techniques but essentially involve mediated face-to-face meetings of the various stakeholder groups in order to achieve a resolution of their differences. When applied to the hen harrier-red grouse conflict in the UK, the process developed dialogue between the groups and highlighted areas for compromise and common-ground (Redpath et al. 2002, 2004). Despite this, however, there was a belief amongst participants that despite the potential agreement about best options for reducing conflicts, a lack of trust between the two groups would prevent implementation. Vinuela and Arroyo (2002), however, reported that such collaboration is possible with examples happening at the local scale in some European countries.
Acknowledgments I thank Pete Robertson, Matt Heydon, Nigel Shelton and two anonymous referees for constructive comments on earlier versions of the manuscript. The manuscript was derived from a wider study into wildlife conflicts funded by the Department for Environment, Food and Rural Affairs (Defra).

Open Access This article is distributed under the terms of the Creative Commons Attribution License which permits any use, distribution, and reproduction in any medium, provided the original author(s) and the source are credited.

\section{References}

Allen DS (2001) Raptors and the rearing of Pheasants, Part II: a preliminary evaluation of techniques to reduce losses of young pheasants to raptors at release pens. ADAS Consulting Ltd. Report to the British Association for Shooting and Conservation

Allen DS, Packer JJ, Blanchard C, Feare CJ (2000) Raptors and the rearing of Pheasants: problems and management needs. ADAS Consulting Ltd. Report to the British Association for Shooting and Conservation

Avery ML, Cummings JL (2004) Livestock depredations by black vultures and golden eagles. Wildlife Damage Management, Internet Center

Avery MI, Winder FLR (1990) Roseate Tern. In: Batten LA, Bibby CJ, Clement P, Elliot GD, Porter RF (eds) Red data birds in Britain. T \& AD Poyser, London, pp 208-212

BASC (2009) Policy on Raptors

BASC (undated) Birds of prey at pheasant release pens: a practical guide for game managers and gamekeepers

Bicknell J, Smart J, Hoccom D, Amar A, Evans A, Walton P, Knott J (2010) Impacts of non-native gamebird release in the UK: a review. RSPB research report no. 40. Sandy, UK

Bomford M, O'Brien PH (1990) Sonic deterrents in animal damage control: a review of device tests and effectiveness. Wildl Soc Bull 18: $411-422$

Bourne J (2001) Prevention of predator damage in poultry flocks. AgriFacts. Practical information for Alberta's agricultural industry. Agdex 450/684-1

Bro E, Arroyo B, Migot P (2006) Conflict between grey partridge Perdix perdix hunting and hen harrier Circus cyaneus protection in France: a review. Wildl Biol 12:233-247

Cade TJ (1986) Reintroduction as a method of conservation. Raptor Res Rep 5:72-84

Cade TJ (2000) Progress in translocation of diurnal raptors. In: Chancellor RD, Meysburg BU (eds) Raptors at risk, World Working Group on Birds of Prey, pp 343-372

Carroll J, Robertson P (1997) Integrating pheasant management and woodland conservation. Game Conservancy Ltd, Fordingbridge

Clements R (2000) Range expansion of the common buzzard in Britain. Brit Birds 93:242-248

Clements R (2002) The common buzzard in Britain: a new population estimate. Brit Birds 95:377-383

Cote IM, Sutherland WJ (1995) The scientific basis for predator control for bird conservation. English Nature Research report No. 144

Cramp S (1980) Handbook of the Birds of Europe, the Middle East and North Africa. Volume II. Hawks to bustards, Oxford University Press

Crooks KR, Soule M (1999) Mesopredator release and avifaunal extinctions in a fragmented system. Nature 400:563-566

Department of Environment and Conservation (DEC) (2007) Fauna note no. 17. Wedge-tailed eagle. Department of Environment and Conservation, Western Australia 
Durdin C (1993) Little terns and kestrels. Brit Wild 4:194-195

Eaton MA, Balmer DE, Bright J, Cuthbert R, Grice PV, Hall C, Haywow DB, Heran RD, Holt CA, Knipe A, Mavor R, Noble DG, Oppel S, Risely K, Stroud DA, Wotton S (2013) State of the UK's Birds (2013) RSPB, BTO, WWT, NRW, JNCC, NIEA and SNH. Sandy, Bedfordshire

Errington P (1956) Factors limiting higher vertebrate populations. Science 124:304-307

Fischer J, Lindenmeyer DB (2000) An assessment of the published results of animal relocations. Biol Conserv 96:1-11

Franklin WL, Powell KJ (1994) Guard llamas: a part of integrated sheep protection. Iowa State University Extension Publication, Ames

Game Conservancy Trust (2003) Woodland conservation and pheasants. Game Conservancy Trust, Fordingbridge

Game Conservancy Trust (2006a) Guidelines for sustainable gamebird releasing. Game Conservancy Trust, Fordingbridge

Game Conservancy Trust (2006b) New guidelines for sustainable gamebird releasing. Game Conservancy Trust, Fordingbridge

Gibbons DW, Amar A, Anderson GQA, Bolton M, Bradbury RB, Eaton MA, Evans AD, Grant MC, Gregory RD, Hilton GM, Hirons GJM, Hughes J, Johnstone I, Newbery P, Peach WJ, Ratcliffe N, Smith KW, Summers RW, Walton P, Wilson JD (2007) The predation of wild birds in the UK: a review of its conservation impact and management. RSPB Research Report no 23. RSPB, Sandy

Graham IM, Redpath SM, Thirgood SJ (1995) The diet and breeding density of common buzzards Buteo buteo in relation to indices of prey abundance. Bird Stud 42:165-173

Graham K, Beckerman A, Thirgood S (2005) Human-predator-prey conflicts: ecological correlates, prey losses and patterns of management. Biol Conserv 122:159-171

Greenwood JJD, Crick HQP, Bainbridge IP (2003) Numbers and international importance of raptors and owls in Britain and Ireland. In: Thompson DBA, Redpath SM, Fielding AH, Marquiss M, Galbraith CA (eds) Birds of prey in a changing environment. Scottish National Heritage. The Stationary Office, Edinburgh, pp 25-50

GWCT (2011) Gamekeepers and wildlife

Harradine J, Reynolds N, Laws T (1997) Raptors and gamebirds-a survey of game managers affected by raptors. BASC, Wrexham

Hudson PJ, Dobson AP, Newborn D (1992) Do parasites make prey vulnerable to predation? Red grouse and parasites. J Appl Ecol 61: 681-692

Hygnstrom ES, Craven SR (2005) Hawks and owls. In: The Handbook: prevention and control of wildlife damage. Internet Center for Wildlife Damage Management, pp E53-E62

Inglis IR (1985) Humane control of rural birds. In: Britt DP (ed) Humane control of land mammals and birds. UFAW, Potters Bar, England, pp $83-93$

Isomuru M, Ratti O, Helle P, Hollmen T (2008) Parasitised grouse are more vulnerable to predation as revealed by a dog-assisted hunting study. Ann Zool Fennici 45:496-502

JNCC (2000) The report of the UK Raptor Working Group. Stationary Office, London

Kenward RE (1999) Raptor predation problems and solutions. J Raptor Res 33(1):73-75

Kenward R (2002) Management tools for reconciling bird hunting and biodiversity. European concerted action within the 5th Framework Program: Reconciling Gamebird Hunting and Biodiversity (REGHAB)

Kenward RE, Hall DG, Walls SS, Hodder KH, Pahkala M, Freeman SN, Simpson VR (2000) The prevalence of non-breeders in raptor populations: evidence from rings, radio-tags and transect surveys. Oikos 91(2):271-279

Kenward RE, Hall DG, Walls SS, Hodder KH (2001) Factors affecting predation by buzzards Buteo buteo on released pheasants Phasianus colchicus. J Appl Ecol 38:813-822
Lees AC, Newton I, Balmford A (2012) Pheasants, buzzards, and trophic cascades. Conserv Lett 6(2):141-144

Linnell JDC, Aanes R, Swenson JE, Odden J, Smith ME (1997) Translocation of carnivores as a method for managing problem animals: a review. Biodivers Conserv 6:1245-1247

Linnell JDC, Odden J, Smith ME, Aanes R, Swenson JE (1999) Large carnivores that kill livestock: do "problem individuals" really exist? Wild Soc Bull 27(3):698-705

Lloyd DEB (1976a) Avian predation of reared pheasants. Unpublished report for the British Field Sports Society, The Game Conservancy, The RSPB and the Wildfowlers Association of Great Britain and Ireland, p 84

Lloyd DEB (1976b) The protection of pheasants in release pens from birds of prey. Report to the British Field Sports Society, Game Conservancy, RSPB and Wildfowlers Association of Great Britain and Ireland, $\mathrm{p} 12$

Manosa S (2002) The conflict between gamebird hunting and raptors in Europe. European Concerted Action within the 5th Framework Program: Reconciling Gamebird Hunting and Biodiversity (REGHAB)

Marcstrom V, Kenward R (1981) Movements of wintering goshawks in Sweden. Swed Wild Res 12(1):1-36

Marquiss M, Madders M, Carss DN (2003a) White-tailed eagles (Haliaeetus albicilla) and lambs (Ovis aries). In: Thompson DBA, Redpath SM, Fielding AH, Marquiss M, Galbraith CA (eds) Birds of prey in changing environment. Scottish Natural Heritage. The Stationary Office, Edinburgh, pp 471-479

Marquiss M, Madders M, Irvine J, Carss DN (2003b) The impact of white-tailed eagles on sheep farming on Mull. Institute of Terrestrial Ecology Contract No. ITE/004/99

Massei G, Quy RJ, Gurney J, Cowan DP (2010) Can translocations be used to mitigate human-wildlife conflicts? Wildlife Res 37:428-439

Millan J, Gortazar C, Tizzani P, Buenestado FJ (2002) Do helminths increase the vulnerability of released pheasants to fox predation? J Helminth 76(3):225-229

Mustin K, Newey S, Irvine J, Arroyo B, Redpath S (2011) Biodiversity impacts of game bird hunting and associated management practices in Europe and North America. The James Hutton Institute Contract Report to the RSPB

Newton I (1993) Predation and limitation of bird numbers. Curr Ornithol 11:143-197

Newton I (1998) Population limitation in birds. Academic, San Diego

Newton I, Marquiss M (1991) Removal experiments and the limitation of breeding density in sparrowhawks. J Anim Ecol 60:535-544

Newton I, Dale L, Rothery P (1997) Apparent lack of impact of sparrowhawks on the breeding densities of some woodland songbirds. Bird Stud 44:129-135

Park KJ, Calladine JR, Graham KE, Stephenson CM, Wernham CV (2005) The impacts of predatory birds on waders, songbirds, gamebirds and fisheries interests. Report to the Scotland's Moorland Forum

Parrott D (2012) Reviews of selected wildlife conflicts and their management. Annex B: approaches to mitigating bird of prey conflicts with pheasants at release pens, outdoor poultry and lambs. Food and Environment Research Agency (now Animal \& Plant Health Agency) Report to Defra

Phillips RL, Cummings JL, Berry JD (1991) Responses of breeding golden eagles to relocation. Wildl Soc Bull 19:430-434

Redpath SM, Thirgood SJ, Leckie FM (2001a) Does supplementary feeding reduce predation of red grouse by hen harriers? J Appl Ecol 38(6):1157-1168

Redpath SM, Clarke R, Madders M, Thirgood SJ (2001b) Assessing raptor diet: comparing pellets, prey remains, and observational data at harrier nests. Condor 103:184-188

Redpath SM, Arroyo BE, Bayfield N, Bacon P, Thirgood, Gutiérrez RJ (2002) Towards a resolution of the raptor-grouse conflict in upland 
Britain - the application of decision modelling with stakeholders. European Concerted Action within the 5th Framework Program: Reconciling Gamebird Hunting and Biodiversity (REGHAB)

Redpath SM, Arroyo BE, Leckie FM, Bacon P, Bayfield N, Gutiérrez RJ, Thirgood SJ (2004) Using decision modelling with stakeholders to reduce human-wildlife conflict: a raptor-grouse case study. Conserv Biol 18:350-359

Redpath SM, Young J, Evely A, Adams WM, Sutherland WJ, Whitehouse A, Amar A, Lambert RA, Linnell JDC, Watt A, Gutiérrez RJ (2013) Understanding and managing conservation conflicts. Trends Ecol Evol 28(2):100-109

Reif V, Tornberg R, Jungell S, Korpimaki E (2001) Diet variation of common buzzards in Finland supports the alternative prey hypothesis. Ecography 24:267-274

Risely K, Massimino D, Newson SE, Eaton MA, Musgrove AJ, Noble DG, Procter D, Baillie SR (2013) The Breeding Bird Survey 2012. BTO Research Report 645. British Trust for Ornithology, Thetford

Robertson PA (1988) Survival of released pheasants, Phasianus colchicus, in Ireland. J Zool (Lond) 214:683-695

Robertson PA, Woodburn MIA, Hill DA (1993a) Factors affecting winter pheasant density in British woodlands. J Appl Ecol 30:459-464

Robertson PA, Woodburn MIA, Neutel W, Bealey CE (1993b) Effects of land use on breeding pheasant density. J Appl Ecol 30:465-477

Rooney E, Montgomery WI (2013) Diet diversity of the common buzzard (Buteo buteo) in a vole-less environment. Bird Stud 60(2):147-155

Rosas-Rosas OC, Bender LC, Valdez R (2008) Jaguar and puma predation on cattle calves in northeastern Sonora, Mexico. Rangel Ecol Manag 61(5):554-560

RSPB (2009) Birdcrime: offences against wild bird legislation in 2009 RSPB (2010) Birdcrime: offences against wild bird legislation in 2010 RSPB (2011) Birdcrime: offences against wild bird legislation in 2011 RSPB (2012) Birdcrime: offences against wild bird legislation in 2012 RSPB (2013) Birdcrime: offences against wild bird legislation in 2013

Sage RB, Ludolf C, Robertson PA (2005) The ground flora of ancient semi-natural woodland in pheasant release pens in England. Biol Conserv 122:243-252

Selas V, Tveiten R, Aanonsen OM (2007) Diet of common buzzards (Buteo buteo) in southern Norway determined from prey remains and video recordings. Ornis Fennica 84:97-104

Sih A, Crowley P, McPeek M, Petranka J, Strohmeier K (1985) Predation, competition, and prey communities. Ann Rev Ecol Syst 16:269-311

Sim IMW, Cross AV, Lamacraft DL, Pain DJ (2001) Correlates of common buzzard Buteo buteo density and breeding success in the West Midlands. Bird Stud 48(3):317-329

Stahl P, Vandel JM, Herrenschmidt V, Migot P (2001) Predation on livestock by an expanding reintroduced lynx population: long-term trend and spatial variability. J Appl Ecol 38:674-687

Stahl P, Ruette S, Gros L (2002) Predation on free-ranging poultry by mammalian and avian predators: field loss estimates in a French rural area. Mammal Rev 32(3):227-234

Stoate C, Thomson DL (1999) Predation and songbird populations. In: Aebischer NJ, Evans AD, Grice PV, Vickery JA (eds) Ecology and conservation of lowland farmland birds. Proceedings of the 1999 British Ornithologists' Union Spring Conference, p 134-139

Stroud DA (2003) The status and legislative protection of birds of prey and their habitats in Europe. In: Thompson DBA, Redpath SM,
Fielding AH, Marquiss M, Galbraith CA (eds) Birds of prey in a changing environment. Scottish National Heritage. The Stationary Office, Edinburgh, pp 51-84

Swan G (2011) Spatial variation in the breeding success of the common buzzard Buteo buteo in relation to habitat type and diet. MSc thesis, Imperial College, University of London, London

Swan RL, Etheridge B (1995) A comparison of breeding success and prey of the common buzzard Buteo buteo in two areas of northern Scotland. Bird Stud 41(1):37-43

Tapper SC (1992) Game heritage. Game Conservancy Trust, Fordingbridge

Thirgood S, Redpath S (2008) Hen harriers and red grouse: science, politics and human-wildlife conflict. J Appl Ecol 45(5):1550-1554

Thirgood S, Woodroffe R, Rabinowitz A (2005) The impact of humanwildlife conflict on human lives and livelihoods. In: Woodroffe R, Thirgood S, Rabinowitz A (eds) People and wildlife. Conflict or coexistence? Cambridge University Press, Cambridge, pp 13-26

Thompson DBA, Redpath SM, Fielding AH, Marquiss M, Galbraith CA (2003) Birds of prey in a changing environment. Scottish Natural Heritage. The Stationary Office, Edinburgh

Tornberg R, Reif V (2007) Assessing the diet of birds of prey: a comparison of prey items found in nests and images. Ornis Fenn 84:21-31

Turner CV (2007) The fate and management of pheasants (Phasianus colchicus) Released in the UK. PhD Thesis, Imperial College, University of London, London

Turner C, Sage R (2003) Fate of released pheasants. Game Conservancy Trust Rev 35:74-75

Valkama J, Korpimaki E, Arroyo B, Beja P, Bretagnolle V, Bro E, Kenward R, Manosa S, Redpath SM, Thirgood S, Vinuela J (2005) Birds of prey as limiting factors of gamebird populations in Europe: a review. Biol Rev 80:171-203

Vinuela J, Arroyo B (2002) Gamebird hunting and biodiversity conservation: synthesis, recommendations and future research priorities. European Concerted Action within the 5th Framework Program: Reconciling Gamebird Hunting and Biodiversity (REGHAB)

Wade DA (1986) Predator damage control: 1980 to 1986. Proc. 12th Vertebrate Pest Conference. University of California, Davis, pp 369-386

Wade DA, Hawthorne DW, Nunley GL, Milton C (1984) History and status of predator control in Texas. Proc. 11th Vertebrate Pest Conference. University of California, Davis, pp 121-131

Waite BC, Phillips RL (1994) An approach to controlling golden eagle predation on lambs in South Dakota. Proc Vertebr Pest Conf 16:28 30

Walls SS, Kenward RE (1995) Movements of radio-tagged common buzzards Buteo buteo in their first year. Ibis 137(2):177-182

Walls S, Kenward R, Holloway G (2004) How common is the common buzzard, Buteo buteo? Biologist 51(1):23-26

Woodroffe R, Thirgood S, Rabinowitz J (2005) People and wildlife: conflict or co-existence. Cambridge University Press, Cambridge

Zuberogoitta I, Martinez JE, Martinez JA, Zabala J, Calvo JF, Castillo I, Azkona A, Iraeta A, Hidalgo S (2006) Influence of management practices on nest site habitat selection, breeding and diet of the common buzzard Buteo buteo in two different areas of Spain. Ardeola 53(1):83-98 